\title{
The distance from the skin to the subarachnoid space can be predicted in premature and former- premature infants
}

\author{
[La distance entre la peau et l'espace sous-arachnoïdien peut être prédite chez les \\ enfants prématurés et les anciens prématurés]
}

\begin{abstract}
Ze'ev Shenkman MD, ${ }^{*}$ Valeria Rathaus MD, $\dagger$ Robert Jedeikin BSc MB CHB FFA, ${ }^{*}$ Osnat Konen MD, $\dagger$ David Hoppenstein MB BCH DA(SA), ${ }^{*}$ Mitchell Snyder PhD, $\ddagger$ Enrique Freud MD\$
\end{abstract}

Purpose: Spinal anesthesia can be technically challenging in young infants. We studied whether the distance between the skin and the lumbar subarachnoid space in premature and former-premature young infants could be predicted prior to lumbar puncture.

Methods: The distance from skin entry point to tip of the spinal needle was measured using a caliper after lumbar spinal anesthesia at the L4-5 interspace. This distance was correlated to the patient's weight, postconceptual age and lumbar ultrasonographic measurement of the skin-to-subarachnoid space and predictive statistical models were sought.

Results: Thirty-five premature or former-premature infants were studied. Three models were examined: all three independent variables, weight and postconceptual age only, and weight only. The model selected contained the weight and postconceptual age, because it had the highest value for adjusted $\mathrm{R}$ squared, as well as the lowest value for the mean squared error. Adding the ultrasonic measurement to the model worsened the results. The statistical model that described the depth of the subarachnoid space at the $L 4-5$ level was $Y=13.19+0.0026 \times W-0.12 \times P C A$, where $Y$ is the distance $(\mathrm{mm})$ from the skin to the subarachnoid space, $W$ is the patient's weight ( $\mathrm{g}$ ) and PCA is the postconceptual age (weeks). Adjusted $\mathrm{R}$ squared was 0.72 , mean square error was 2.63 and $P<10^{-9}$.

Conclusion: The distance between the skin and the subarachnoid space at the level of L4-5 interspace can be predicted using a statistical model based on the infant's weight and postconceptual age. Spinal ultrasound has no value in L4-5 subarachnoid space depth prediction.
Objectif : La rachianesthésie peut être une technique intéressante à utiliser chez de jeunes enfants. Nous avons vérifié si la distance entre la peau et l'espace sous-arachnoïdien lombaire pouvait être prédite avant la ponction lombaire chez les enfants prématurés et anciens prématurés.

Méthode : La distance entre le point d'entrée cutanée et le bout de l'aiguille rachidienne a été mesurée à l'aide d'un compas à calibrer après la rachianesthésie au niveau L4-5. Cette distance a été mise en corrélation avec le poids du patient, l'âge gestationnel et la mesure échographique lombaire de la distance entre la peau et l'espace sousarachnoïdien ; des modèles statistiques de prédiction ont été recherchés.

Résultats : L'étude a porté sur 35 bébés prématurés ou anciens prématurés. Trois modèles ont été examinés : les trois variables indépendantes, le poids et l'âge gestationnel seulement, le poids seulement. Nous avons choisi le modèle comportant le poids et l'âge gestationnel, car il présentait la valeur la plus élevée pour le $R$ carré ajusté, et la plus basse valeur pour l'erreur moyenne au carré. Le fait d'ajouter la mesure échographique au modèle a détérioré les résultats. Le modèle statistique qui décrivait la profondeur de l'espace sous-arachnoïdien au niveau L4-5 a été $Y=13,19+0,0026 \times W-0,12 \times A P C$, où $Y$ est la distance $(\mathrm{mm})$ entre la peau et l'espace sous-arachnoïdien, $W$ est le poids du patient (g) et APC est l'âge postconception (semaines). Le R carré ajusté a été de 0,72, l'erreur moyenne au carré a été de 2,63 et $P<$ $10^{-9}$.

Conclusion : La distance entre la peau et l'espace sous-arachnoïdien au niveau de l'espace intervertébral L4-5 peut être prédite par un modèle statistique fondé sur le poids et l'âge postconception de l'enfant. L'échographie rachidienne n'a pas de valeur pour prédire la profondeur de l'espace sous-arachnoïdien à L4-5.

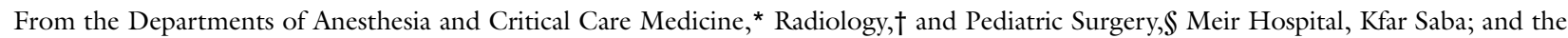
Sackler Faculty of Medicine, Tel Aviv University, Tel Aviv; and the Department of Mathematics and Statistics, $\ddagger$ Bar Ilan University, RamatGan, Israel.

Address correspondence to: Dr. Ze'ev Shenkman, Department of Anesthesia and Intensive Care, Meir Hospital, Tshernichovsky Street,

Kfar Saba 44281, Israel. Phone: 972-9-747-1545; Fax: 972-9-747-1298; E-mail: shlomsh1@netvision.net.il

Accepted for publication May 20, 2003

Revision accepted October 20, 2003. 


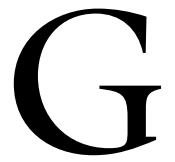

ENERAL anesthesia or sedation in premature and former-premature infants is associated with a risk of up to $90 \%$ postoperative apnea, hypoxemia or bradycardia. ${ }^{1-6}$ In contrast, spinal anesthesia $(\mathrm{SA})^{3,7,8}$ markedly reduces the risk of apnea ${ }^{3}$ hypoxemia and bradycardia. ${ }^{5}$

Since lumbar puncture (LP) may be challenging in small infants, subarachnoid space depth prediction preoperatively may shorten LP time and lessen infant discomfort. We undertook this study to seek a mathematical model for skin-to-subarachnoid space distance using patient weight, postconceptual age (PCA) and spinal ultrasonography in premature and former-premature infants.

\section{Methods}

Preterm and former-preterm infants (gestational and PCA below 37 and 60 weeks, respectively) undergoing SA were prospectively studied with local Ethics Committee approval and parental consent.

Anesthetic management was standardized. ${ }^{7,8}$ With the patient being seated, a one-inch, 25-gauge Quincke spinal needle (Beckton Dickinson, Franklin Lakes, NJ, USA) was inserted in the midline, slightly cephalad into the L4-5 interspace, removing the stylette intermittently to reveal cerebrospinal fluid (CSF). Subarachnoid placement was confirmed by CSF free flow and by the development of SA. The needle was grasped using a mosquito forceps abutted to the patient's back and removed. The distal portion was bent over the forceps and cut from its proximal part. Its length was measured using a caliper (Mauser, Bruehl, Germany) by a single investigator and the average of three measurements was calculated. Measurements deviating more than $0.1 \mathrm{~mm}$ from one another were excluded and repeated.

Postoperatively, with the patient positioned prone on a pillow, depth of the L4-5 subarachnoid space was measured using an Apogee System (Advanced Technology Laboratories, Bothell, WA, USA) equipped with a 7 to $10 \mathrm{MHz}$ linear-array ultrasound transducer. The average of two measurements was used for statistical analysis. A single ultrasonographer performed all but two examinations. The ultrasonographers were blinded to the needle length measurement.

\section{Statistical analysis}

A multiple linear regression was fitted to the data. The dependent variable was the measured needle length and the potential independent variables were the weight, PCA and the ultrasonic measurement. Three models were examined: all three independent variables, weight and PCA only, and weight only.

TABLE I Demographics and subarachnoid space depth

Gestational age (weeks)

Birth weight $(\mathrm{g})$

Postconceptual age (weeks)

Current weight $(\mathrm{g})$

Measured subarachnoid space depth $(\mathrm{mm})$

Ultrasonic subarachnoid space

Data are presented as mean \pm standard deviation of the mean (range).

TABLE II The difference between measured and predicted subarachnoid space

\begin{tabular}{cc}
\hline Measured to predicted difference $(\mathrm{mm})$ & Number of patients $(n=35)$ \\
$<0.5$ & 11 \\
$0.5-1.0$ & 13 \\
$1.0-1.5$ & 3 \\
$1.5-2.0$ & 1 \\
$2.0-2.5$ & 1 \\
$2.5-3.0$ & 3 \\
$3.0<$ & 3 \\
\hline
\end{tabular}

Regression was used for data analysis using Microsoft Excel, version 2000.

\section{Results}

Thirty-five infants were studied. Demographic variables and depth measurements are presented in Table I. No SA failure occurred.

Ultrasonography was abandoned after 19 patients since the addition of the ultrasonic measurement to the model lowered its predictive value by decreasing the adjusted $\mathrm{R}$ squared $\left(\mathrm{aR}^{2}\right)$ and increasing the mean squared error (MSE).

The statistical model was $\mathrm{Y}=13.19+0.0026 \times \mathrm{W}$ $-0.12 \times$ PCA $[\mathrm{Y}=$ the distance $(\mathrm{mm})$ from skin to the subarachnoid space at $\mathrm{L} 4-5, \mathrm{~W}=$ patient's weight $(\mathrm{g})$ and PCA (weeks)]. $\mathrm{aR}^{2}$ was 0.72 , MSE was 2.63 and $P<10^{-9}$. The model and the $\mathrm{aR}^{2}$ and MSE were similar to those found after the inclusion of the first 19 patients. The measured-to-predicted depth differences are presented in Table II.

\section{Discussion}

Although SA is usually straightforward, it may be technically challenging in small infants. The proposed arithmetic calculation for subarachnoid depth prediction in premature and former-premature infants may aid anesthesiologists and pediatricians by facilitating accurate spinal needle placement, decreasing patient discomfort and shortening of operating theatre time. Nevertheless, this assumption remains to be proven by 
measuring these end-points with patients randomized according to anesthesiologist's awareness of the predicted depth.

Both CSF flow and signs of SA substantiate the accuracy of the subarachnoid depth measurement. The wide range of depths can be explained by the ranges of body weight and PCA (Table I). We hypothesized the subarachnoid space depth will correlate positively with patient weight and PCA and would be predicted by ultrasonographic measurement. However, the model selected contained the weight and PCA only because these variables had the highest predictive value.

Formulae for calculation of the subarachnoid space depth have been produced previously. ${ }^{9,10}$ Bonadio et al. found a positive correlation between subarachnoid space depth and body surface area (rather than with either patient weight or height independently), in a study of 158 subjects aged one day to 18 yr. $^{9}$ Craig et al. found a positive correlation between depth of the subarachnoid space and patient height in 107 subjects aged 0.01 to 16 yr. $^{10}$ Our model may be more precise and accurate in this unique and homogenous population of young premature and former-premature infants, compared to models based on patients with such a wide range of age. Depth estimation was within $2 \mathrm{~mm}$ in 28 of our 35 patients $(80 \%)$ and within 3 $\mathrm{mm}$ in 32 of the patients (91\%), compared with $5 \mathrm{~mm}$ in most young children studied by Bonadio et al. ${ }^{9} \mathrm{No}$ numerical data were presented in Craig's study. ${ }^{10} \mathrm{In}$ addition, measuring body length in young infants may be subject to error and may have affected the results of former studies. We elected to base our analysis on more reliable variables such as body weight and PCA.

Our method has potential weaknesses. First, inaccuracy of depth measurement may have resulted from the infinite number of angles of needle insertion that are possible, each angle yielding a distinct distance. Second, it may be argued that the direction of the ultrasonic scan should be similar to LP i.e., parallel to the spinous processes. However, the diagonal distance is proportional to the perpendicular depth of the subarachnoid space. Therefore, scan direction probably did not affect the results. Ultrasonographic measurement inaccuracy may also result from variable degrees of transducer pressure on the skin by the operator. Also, ultrasonography may have been better performed with the patient held in the same position as during LP, perhaps in the operating theatre just prior to LP. Logistically, this is impractical, expensive and cumbersome for routine practice. It may increase patient discomfort while being positioned uncomfortably for a longer period of time and prolong operating room stay. Finally, ultrasonographic measure- ment may be less accurate in the moving and struggling seated infant.

In conclusion, a statistical model based on patient weight and PCA to predict depth of the L4 -5 subarachnoid space was developed in infants weighing 1710 to 5800 g, PCA 35.0 to 53.0 weeks. The predicted depth can be calculated for every single patient or alternatively, a table of predicted depths according to weight and PCA can be used (available as additional material at www.cja-jca.org). To ease the performance of SA in small infants we propose the use of a needle with marked gradations.

\section{References}

1 Cote CJ, Zaslavsky A, Downes JJ, et al. Postoperative apnea in former preterm infants after inguinal herniorrhaphy. Anesthesiology 1995; 82: 809-22.

2 Kurth CD, Spitzer AR, Broennle AM, Downes JJ. Postoperative apnea in preterm infants. Anesthesiology 1987; 66: 483-8.

3 Welborn LG, Rice LJ, Hannallah RS, Broadman LM, Ruttimann UE, Fink R. Postoperative apnea in former preterm infants. Prospective comparison of spinal and general anesthesia. Anesthesiology 1990; 72: 838-42.

4 Welborn LG, Hannallah RS, Luban NL, Fink R, Ruttimann UE. Anemia and postoperative apnea in former preterm infants. Anesthesiology 1991; 74: 1003-6.

5 Krane EJ, Haberkern CM, Jacobson LE. Postoperative apnea, bradycardia, and oxygen desaturation in formerly premature infants: prospective comparison of spinal and general anesthesia. Anesth Analg 1995; 80: 7-13.

6 Malviya S, Swartz J, Lerman J. Are all preterm infants younger than 60 weeks postconceptual age at risk for postanesthetic apnea? Anesthesiology 1993; 78 : 1076-81.

7 Shenkman Z, Hoppenstein D, Litmanowitz I, et al. Spinal anesthesia in 62 premature, former-premature or young infants-technical aspects and pitfalls. Can J Anesth 2002; 49: 262-9.

8 Sethna NF, Berde CB. Pediatric regional anesthesia. In: Gregory GA (Ed.). Pediatric Anesthesia, 4th ed. New York: Churchill Livingstone Inc.; 2002: 267-316.

9 Bonadio WA, Smith DS, Metrou M, Dewitz B. Estimating lumbar-puncture depth in children (Letter). N Engl J Med 1988; 319: 952-3.

10 Craig F, Stroobant J, Winrow A, Davies H. Depth of insertion of a lumbar puncture needle. Arch Dis Child 1997; 77: 450. 